\title{
Liver-stage specific response among endemic populations: diet and immunity
}

\author{
Sarat Kumar Dalai ${ }^{1}$, Naveen Yadav ${ }^{1}$, Manoj Patidar ${ }^{1}$, Hardik Patel ${ }^{1}$ and Agam Prasad Singh ${ }^{2}$ \\ 1 Institute of Science, Nirma University, Ahmedabad, India \\ 2 Infectious Diseases Laboratory, National Institute of Immunology, New Delhi, India
}

\section{Edited by:}

Ute Frevert, New York University School of Medicine, USA

Reviewed by:

Laurent Renia, Agency for Science, Research and Technology, Singapore Alexander Pichugin, Walter Reed Army Institute of Research, USA

\section{*Correspondence:}

Sarat Kumar Dalai, Institute of Science, Nirma University, Sarkhej-Gandhinagar Highway, Ahmedabad 382481, Gujarat, India e-mail: sarat.dalai@nirmauni.ac.in
Developing effective anti-malarial vaccine has been a challenge for long. Various factors including complex life cycle of parasite and lack of knowledge of stage specific critical antigens are some of the reasons. Moreover, inadequate understanding of the immune responses vis-à-vis sterile protection induced naturally by Plasmodia infection has further compounded the problem. It has been shown that people living in endemic areas take years to develop protective immunity to blood stage infection. But hardly anyone believes that immunity to liver-stage infection could be developed. Various experimental model studies using attenuated parasite suggest that liver-stage immunity might exist among endemic populations. This could be induced because of the attenuation of parasite in liver by various compounds present in the diet of endemic populations.

Keywords: Plasmodia, liver-stage immunity, natural habit, sterile protection, chloroquine and chemoprophylaxis

\section{INTRODUCTION}

Malaria along with HIV and TB poses great challenge to human health. More than 200 million people are at high risk and millions are dying (particularly, children) every year across the globe (1). Although anti-malarial drugs have helped bring down the severity and mortality of malaria in endemic regions, emergence of drug resistant parasite poses a great challenge to the human health prompting the urgent need for vaccine(s). Developing effective vaccines, however, has been challenging because of the complex life cycle of Plasmodia, which starts with the asymptomatic liver stage followed by the symptomatic blood stage infection (Figure 1). Various studies have shown the generation of protective immunity against the blood stage infection after repeated exposure to the parasite (2), but it is questionable against the liver stage $(3,4)$. However, experiments, using radiation or genetically attenuated sporozoite (RAS or GAS) that fails to complete their developmental cycle in liver, demonstrate the induction of sterile immunity in rodents and humans $(2,5-7)$. Even chemoprophylaxis and sporozoite (CPS) immunization that kills the parasite at early stage in RBCs (restricting its development to the liver) has shown similar results $(2,5,7,8)$. Although humoral and cell mediated responses are required to develop protection, $\mathrm{CD} 8^{+} \mathrm{T}$ cell response, generated by attenuated parasite, seems to play a critical role in providing protracted protection at liver stage $(2,3,5-8)$. These findings prompted us to think that there is possibility of inducing liverstage specific immune responses in humans by the parasite that might be attenuated or restricted to liver during natural infection.

People living in different subcontinents with high endemicity for malaria have been shown to have varying degree of susceptibility to infection (Table 1) (1). It becomes difficult to protect the host if the parasite enters the blood stage without being interrupted at liver stage as parasite load in blood could be uncontrollably high. Therefore, restricting the parasite to the liver could generate the protective immunity against malaria indicating the differential susceptibility of endemic people to challenge. Food habits have been shown to have a major impact on the health and modulation of immune response. For example, in India, people consume many herbs/spices as a part of their daily diet, which has been shown to have an anti-malarial activity, as explained later. This article has made an attempt to explain how parasites could be attenuated or restricted "naturally" to either liver stage or blood stage by the diet of people living in malaria endemic areas, potentially helping generate liver-stage specific immune responses.

\section{CHALLENGES IN MALARIA VACCINE DEVELOPMENT}

Sterile protection to malaria even in endemic populations is not yet fully understood. Even vaccination has failed to induce the desired protection because of involvement of many complex factors (9-16). However, researchers have designed strategies that could provide sterile protection. Both blood and liver vaccination strategies are under different phases of clinical trials (17). The majority of the efforts to understand the immune response against Plasmodia infection in humans are directed against blood stage infection. But none of the blood stage vaccine candidates that have been tried so far demonstrated appreciable efficacy (18, 19). The same is also true for the liver-stage subunit vaccine candidates (20). Moreover, unlike the rationale of choosing blood stage vaccine candidates, the antigens for liver-stage vaccines have not been selected based on the understanding of protective immune response in humans against liver-stage infection, a probable reason for not having the right liver stage antigenic target. RAS, GAS, and CPS have shown appreciable efficacy $(2,5-8)$. Despite promising results, these approaches might not be feasible to adopt for mass vaccination. Considering the world population at risk of malaria, the feasibility of making billions of doses and maintaining the quality are very challenging. Second, GAS has been shown to revert to infectious parasite $(21,22)$ posing a threat to people expected to take vaccine for prophylaxis. Although CPS immunization is an 


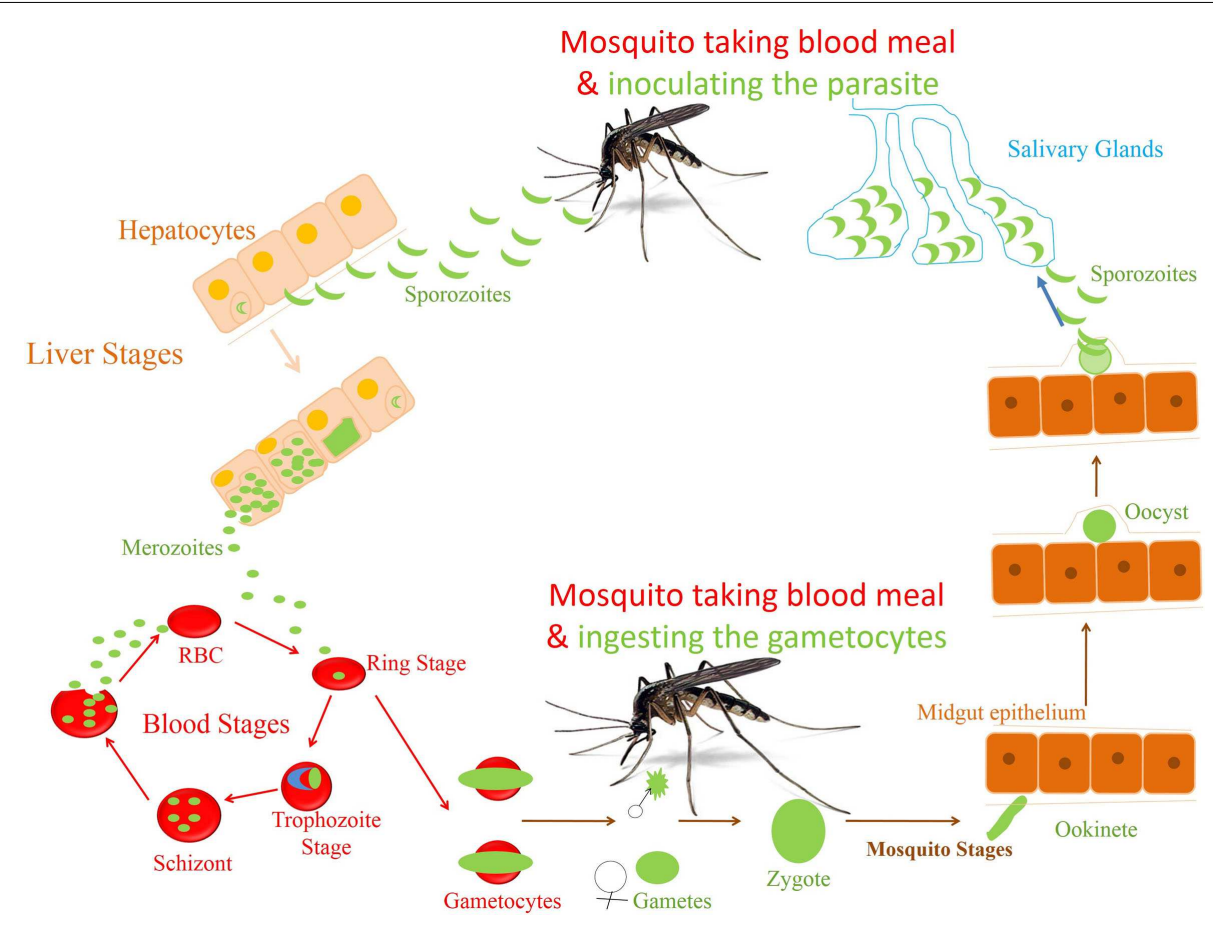

FIGURE 1 | Life cycle of Plasmodium falciparum. The life cycle of parasite $P$. falciparum starts in human with inoculation of parasite through mosquito. From the site of injection, sporozoite (SPZ) reaches to the liver and infect hepatocytes. The SPZ multiplies and produces thousands of blood stage infective merozoites. These merozoites enter the blood stream and infect the
RBCs to start the erythrocytic cycle of parasite. In RBC, they go through different stages of development before they release the merozoites to infect new RBCs. A small percentage of asexual parasite transforms into sexual form, i.e., gametocytes, which finally develop into sporozoites in the mosquitoes. attractive vaccination approach, drug resistant parasites and side effects of drug possess challenges. Therefore, approaches like a subunit vaccine will be good alternative. Inducing sterile protection by subunit vaccines requires identification of the right antigenic targets. From the experience of LSA-1 as vaccine candidate, it is critical to have new targets that would induce humoral and $\mathrm{T}$ cell responses. Unless we understand the nature of immune response vis-à-vis protection that exists in endemic population, it will be difficult to identify the targets. Because of the lack of knowledge of liver-stage specific immune responses among endemic populations, it is strongly believed that protective immunity to liver stage does not exist; hence efforts to make a liver-stage vaccine have not been prioritized, a reason in our opinion, for not having an effective vaccine against malaria even decades after the trial of RAS vaccination.

\section{EXISTENCE OF NATURAL IMMUNITY TO LIVER STAGE}

Many factors including genetic diversity, environmental conditions, and mosquito species do contribute to the differential susceptibility to infection (23-25). While this is true for most of the people living in different parts of the world, we strongly feel that the gain of such differential protection could have a direct correlation with the ability of endemic populations to generate liver-stage specific immune responses. Even though there is blood stage specific protective immunity in people in malaria endemic areas (2), often they come down with the infection (3). It indicates that protective immunity against the blood stage might not be sufficient, and therefore, liver-stage immunity is required to eliminate the parasite. Experiments suggest that achieving protective immunity requires both $\mathrm{CD}^{+} \mathrm{T}$ cells and antibody response (26) because $\mathrm{CD}^{+} \mathrm{T}$ cells are essential for liver-stage parasite while humoral response is key to control blood stage (27). Although fewer studies have been done in endemic populations, there is clear indication that immune responses to liver stage leading to protection could be achievable. In support of this, the studies conducted by the research groups of Marc Connelly and Adrian Hill in Africa have shown that protection, although among a minute endemic population, correlates with immune response to liver-stage antigen (LSA) $(23,28,29)$. As discussed before, immunization with attenuated or drug restricted Plasmodium falciparum sporozoite is very effective in both animal models and in humans. Results indicate that protection is achievable either by vaccinating the host or exposing the host to the parasite attenuated or restricted naturally.

\section{ENDEMICITY VS. INFECTIVITY AMONG ENDEMIC POPULATIONS}

Our analysis of WHO data shows that people of certain subcontinents are less susceptible to malaria than others having similar risk of high endemicity (Table 1). People living in Indian subcontinents have been showing lower incidence of malaria compared to other countries having endemicity either lower or higher than India. India is having $0.48 \%$ malaria incidence, which is seven times lower than that of Madagascar, i.e., 3.50\%. Malarial endemicity of India is $22 \%$ while that of Madagascar is $30 \%$ (Table 1). Various states 
Table 1 | List of countries with their Union Territory population, malaria endemic population, malaria confirmed cases, percent population at high risk, and percent incidence of malaria in 2011.

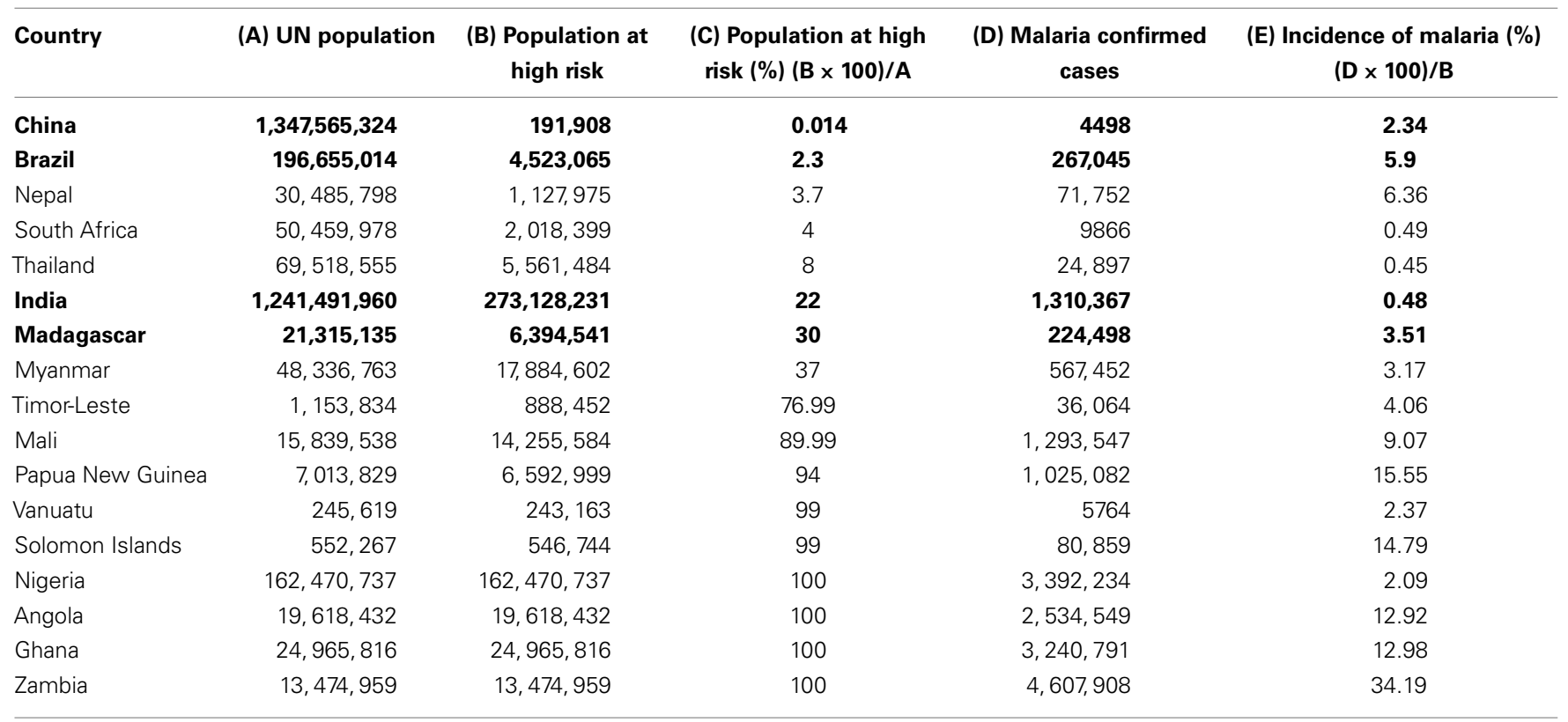

of India, e.g., Arunachal Pradesh, Meghalaya, Mizoram, Tripura, Jharkhand, and Odisha are having high risk (72-100\%) of infection (Table 2) (30), but the rate of malaria infection is about $0.72 \%$. In contrast, China and Brazil where only $0.014-2.3 \%$ population at high risk but incidence of malaria is $2.3-5.9 \%$, which is threefold to eightfold higher than that of India (Table 1), based on the data of 2011. Further analysis of data from 2008 to 2012 suggests that the incidence of malaria remain consistently low even if the high risk population has not decreased significantly as compared to countries like China and Brazil (Figure 2). It is possible that people living in specific regions of high endemic zones of African countries or Brazil might have the similar trends of malaria incidence. It is known that immune responses against blood stage infection are the major factor in providing protective response. However, it is possible that the low incidence of Malaria among endemic populations like in India could be due to the contribution of the liver-stage immune responses generated among them. This might be because of their unique diets playing an important role in attenuating the parasite, a critical factor in generating liver-stage specific response.

\section{PROMOTING LIVER-STAGE IMMUNE RESPONSES BY NATURALLY ATTENUATED PARASITE}

Based on our understanding from various reports, it is possible that many compounds derived from the herbs/spices could attenuate the parasite provoking immune responses to malaria. People, especially those living in the continents of Asia and Africa consume herbs and spices as part of their daily diet that have many medicinal effects; e.g., turmeric, garlic, and black pepper are consumed daily by Indians in almost all food items (31-34). The compounds from various sources listed in Table 3 are shown to act on blood or liver stage parasite. It is possible that some of those compounds help induce liver-stage specific immune responses.
Quinine, arabinogalactan, curcumin, piperine, ellagic acid, quercetin, alkaloids, flavonoids, cinnamic acid derivatives, and allicin to name a few compounds are known to have anti-malarial activity, present in the diet. Many anti-malarial drugs target heme polymerization, essential for parasite to complete its life cycle. Quercetine (apples, oranges, lemons, onions, nuts, garlic, and neem leaves) is known to act on the blood stage parasite by preventing heme polymerization through sequestration of free hemin by forming quercetin-hemin complex (e.g., against $P$. falciparum 3D7) (35). It has also shown to inhibit parasite growth in a dose dependent manner by interfering in the permeability pathways. Quinine (grapefruit, lime, pomegranate, and parsley) also prevents heme polymerization as well as binds to the DNA of parasite at schizont stage and blocks its reproduction (36, 37). Ellagic acid (strawberry, pomegranates and the best source, red raspberry seeds/red Raspberries) has been shown to act on mature trophozoite and young schizont of blood stage parasite while inhibiting hemozoin formation $(38,39,63)$. It has also been shown that ellagic acid potentiates the activity of anti-malarial drugs like chloroquine, mefloquine, artesunate, and atovaquone. According to a curative test, the $\mathrm{ED}_{50}$ of ellagic acid for Plasmodium vinckeipetteri was around $1 \mathrm{mg} / \mathrm{kg} /$ day by the intraperitoneal route. Under the same conditions, artesunate, the most effective semi-synthetic derivative of artemisinin, shows an inferior $\mathrm{ED}_{50}$ of $5 \mathrm{mg} / \mathrm{kg} /$ day. Several studies treating mice intra-peritoneally with ellagic acid before parasite inoculation showed high-level reduction (between 79 and 93\%) of parasitemia by day 6 post-infection suggesting a prophylactic effect of ellagic acid $(38,39,63)$.

Arabinogalactan (tomatoes, carrots, pears, coconut, leek, onion, spinach, broccoli, avocado, eggplant, mango, apples, apricot, banana, radish, turmeric, echinacea tea, and marshmallow root) enhances monocytes production and also activates macrophages that play an important role in phagocytosis of the parasite, thus 
Table 2 | List of states of India with their population, malaria endemic population, malaria confirmed cases, percent population at high risk, and percent incidence of malaria.

\begin{tabular}{|c|c|c|c|c|c|}
\hline State & (A) Population & $\begin{array}{l}\text { (B) Population at } \\
\text { high risk }\end{array}$ & $\begin{array}{l}\text { (C) Population at high } \\
\text { risk }(\%),(B \times 100) / A\end{array}$ & $\begin{array}{c}\text { (D) Malaria confirmed } \\
\text { cases }\end{array}$ & $\begin{array}{l}\text { (E) Incidence of malaria (\%), } \\
(D \times 100) / B\end{array}$ \\
\hline Mizoram & $1,091,014$ & $1,091,014$ & 100 & 8861 & 0.81 \\
\hline Arunachal Pradesh & $1,382,611$ & $1,257,586$ & 91 & 13,950 & 1.11 \\
\hline Jharkhand & $32,966,238$ & $28,791,697$ & 87 & 160,653 & 0.56 \\
\hline Odisha & $41,947,358$ & $36,494,063$ & 87 & 308,968 & 0.85 \\
\hline India & $1,210,569,573$ & $26,63,25,306$ & 22 & $1,310,656$ & 0.49 \\
\hline
\end{tabular}

\section{WHO Report: Malaria Incidences}

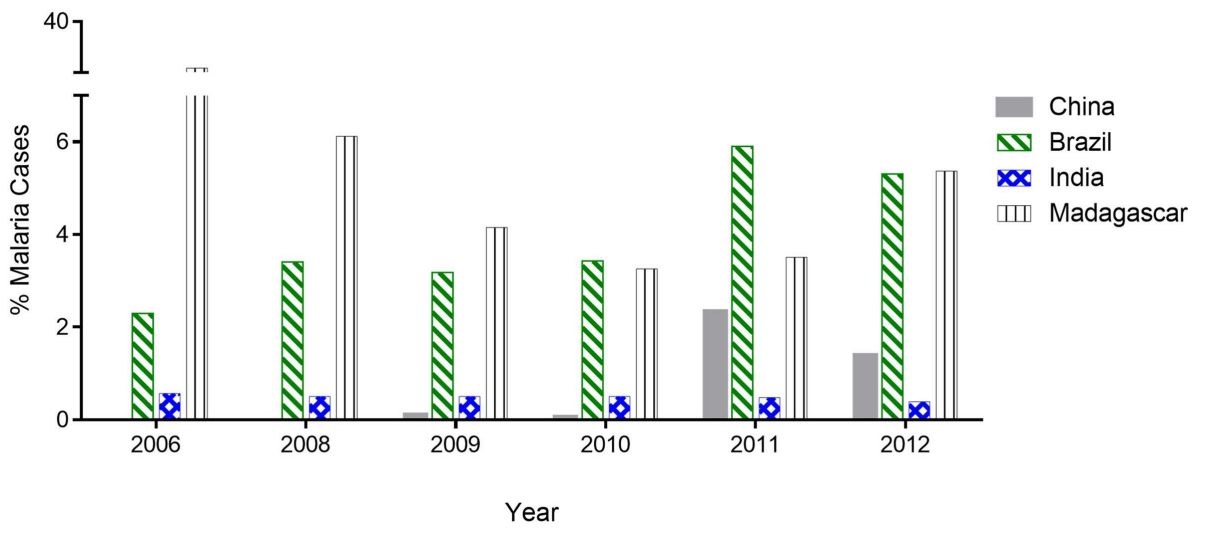

FIGURE 2 | Malaria incidences based on WHO report analysis. The data show the \% of malaria cases (in China, Brazil, India, and Madagascar) during 2006-2012 reported in World Malaria Report. India and Madagascar have comparative high endemicity but varying infectivity whereas China and Brazil having low endemicity but proportionally higher infectivity. lowering the parasite load, and presenting parasite antigens to help potentiate the liver-stage specific $\mathrm{T}$ cell responses $(40,41)$. Quinones (basil oil) inhibit the parasite development at schizont stage by blocking its mitochondrial electron transport and respiratory chain without affecting the host $(42,43)$.

Curcumin (turmeric) acts by damaging the parasite DNA and altering the histone acetylation that accounts for the parasiticidal activity on blood stage parasite (43-48). It has been shown that curcumin inhibits chloroquine-resistant $P$. falciparum growth in a dose dependent manner with an $\mathrm{IC}_{50}$ of $5 \mu \mathrm{M}$ (46). Furthermore, oral administration of curcumin to mice infected with Plasmodium berghei reduces blood parasitemia by $80-90 \%$ and enhances the survival. Padmanaban et al. evaluated the in vivo efficacy of the curcumin-artemisinin combination (46). The results indicated that a, J3-arteether or curcumin monotherapy at the indicated doses prolongs the survival of $P$. berghei-infected mice but does not confer complete protection. However, combining curcumin with a, J3-arteether treatment reduces the infectivity further resulting $100 \%$ protection. Consumption of black pepper, source of piperine, is very common even among non-endemic populations. Piperine has been shown to enhance the bioavailability of curcumin by 2000 -fold (33). The amount of curcumin consumed by endemic population (e.g., India) appears to support the fact that it would be enough to attenuate the parasite in the liver $(34,49-51)$. Cinnamic acid (cinnamon) derivatives have been shown to act at the young (ring) and the mature (trophozoite) stages of parasite development by inhibition of lactate transport or of mitochondrial respiration required for energy generation $(52,53,64)$.

Allicin (garlic cloves) has been shown to prevent the parasite invasion in hepatocytes, reduce parasite load in blood, and enhance survival. It has been shown that the circumsporozoite protein (CSP) of Plasmodium sporozoites is proteolytically processed by a parasite-derived cysteine protease, and this processing event is associated with sporozoite invasion of host cells (54). It is found that 10,25 , or $50 \mu \mathrm{m}$ allicin inhibit CSP cleavage, which is comparable to that observed with $10 \mu \mathrm{m}$ E-64, a cysteine protease inhibitor that inhibits CSP processing and prevents invasion of host cells in vitro and in vivo. Mice injected with allicin showed reduced parasitemia compared to controls. Furthermore, treatment of sporozoite with allicin before injecting into mice completely prevented malaria infection suggesting allicin might directly attenuate the parasite (55). The protective effect of allicin seems to be influenced by improved host immune responses. It has been demonstrated in a rodent malaria model of Plasmodium yoelli (17XL) infection that allicin treatment enhances the production of pro-inflammatory mediators like IFN- $\gamma$, TNF, IL-12p70, and NO. 
Table 3 |The compounds derived from various sources with their anti-malarial activity, mode of action and estimated concentration.

\begin{tabular}{llll}
\hline Fruits or herbs & Compound present & Estimated concentration & Mode of action (anti-malarial activity) \\
\hline Apples, oranges, & Quercetine (flavonoid) & $\begin{array}{l}32 \mathrm{mg} / 100 \mathrm{~g} \text { of red onion; } \\
\text { Daily intake } 12.9 \mathrm{~g} / \text { day) }\end{array}$ & $\begin{array}{l}\text { Inhibition of heme polymerization by chelating free } \\
\text { available hemin for polymerization }\end{array}$ \\
lemons, onions, nuts, &
\end{tabular}

\begin{tabular}{ll}
\hline Grapefruit, lime, & Quinine (alkaloids) \\
pomegranate, parsley &
\end{tabular}<smiles>O=c1c(O)c(-c2ccc(O)c(O)c2)oc2cc(O)cc(O)c12</smiles>

Strawberry,

pomegranates and the

best source, red

raspberry seeds/red

raspberries
100 mg total alkaloids,

including quinine in a cup

of traditional quinine bark

tea
Blocks malaria from reproducing by binding to the

parasite's DNA

Inhibition of hemozoin bio-crystallization, which facilitates the aggregation of cytotoxic heme. Free cytotoxic heme accumulates in the parasites, causing their deaths.
$(36,37)$

Inhibition of $\beta$-hematin (hemozoin) formation

$(38,39)$

Ellagic acid (polyphenol) $50.06 \mathrm{mg} / 10 \mathrm{gm}$ of

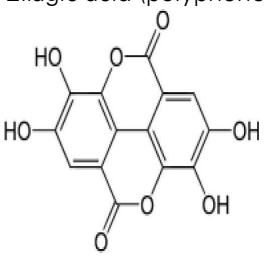

strawberry
Act on trophozoite and early schizont forms of the parasites. This erythrocytic stage of the malaria life cycle is the most metabolically active phase, with protein, RNA, and DNA synthesis taking place.
Tomatoes, carrots, pears, coconut, leek, onion, spinach, broccoli, avocado, eggplant, mango, apples, apricot, banana, radish, turmeric, echinacea tea, marshmallow root

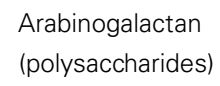

Arabinogalactan (polysaccharides)

$15-25 \%$ in larch
Macrophage activator

Support the monocyte production
$(40,41)$

Basil oil
(4urmeric


Table 3 | Continued

\begin{tabular}{|c|c|c|c|c|}
\hline Fruits or herbs & Compound present & Estimated concentration & Mode of action (anti-malarial activity) & Reference \\
\hline Garlic cloves & $\begin{array}{l}\text { Allicin, organosulfur } \\
\text { compound }\end{array}$ & $\begin{array}{l}1-3 \%(2.8-7.7 \mathrm{mg} / \mathrm{g} \text { found } \\
\text { in Romanian red) }\end{array}$ & $\begin{array}{l}\text { Inhibits circumsporozoite protein processing and } \\
\text { prevents sporozoite invasion of host cells in vitro. In vivo } \\
\text { mice injected with allicin had decreased Plasmodium } \\
\text { infections compared to controls } \\
\text { When sporozoites were treated with allicin before } \\
\text { injection into mice, malaria infection was completely } \\
\text { prevented } \\
\text { Immunomodulatory activities (preferentially enhances } \\
\text { pro-inflammatory immune responses) }\end{array}$ & $(54-56)$ \\
\hline
\end{tabular}

Fenugreek

In leaves: alkaloids, saponin, tannin like phenolic compounds, flavonoids and steroids<smiles>O=c1cc(-c2ccccc2)oc2ccccc12</smiles>

Fenugreek contains 35\% alkaloids and $4.8 \%$ saponin

Hemozoin inhibitors

The alkaloidal, ethanol, and butanol extract of fenugreek has been documented to possess anti-plasmodial activity against in vitro culture of chloroquine sensitive and resistant Plasmodium falciparum

Presence of flavonoids and polyphenols has been found to be responsible for powerful anti-oxidant activity Fenugreek seeds also have capacity to increase the immunity power and to fight against the parasites
Resveratrol (stilbenoid, a type of natural phenol)

juice, berries, e.g., blueberries and black berries<smiles>O=c1c(O)c(-c2ccc(O)c(O)c2)oc2cc(O)cc(O)c12</smiles>

$0.01-0.26 \mathrm{mg}$ in peanuts
Treatment of parasite-infected red blood cells with resveratrol significantly reduces their ability to adhere to the body's cells lining small blood vessels. That reduction in binding to blood vessels is predicted to greatly lessen the probability of developing severe clinical manifestations of malaria, according to the study.
N/A N/A
Nausea and vomiting are also common symptoms of malaria, which may explain the widespread use of ginger as one component of traditional remedies for malaria It stimulates production of the main anti-oxidant enzyme glutathione peroxidase, this detoxification-related enzyme improves the liver function and binds toxins. The compounds of ginger inhibit the malaria parasite.
Cold-pressed coconut oil, fresh and dried coconut, coconut milk, bitter melon

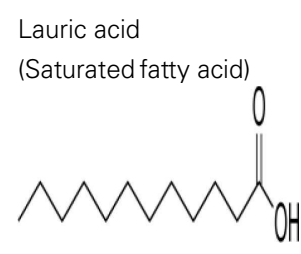

ferulic acid and p-coumaric acid
Pure coconut oil contains about $50 \%$ lauric acid
When lauric acid is converted into monolaurin, a $(61,62)$ monoglyceride compound, which exhibits antiviral, antimicrobial, anti-protozoal, and anti-fungal properties. It acts by disrupting the lipid membranes in organisms like fungus, bacteria, and viruses, thus destroying them Coconut has anti-oxidant compounds 
The numbers of CD4+ T cells, DCs, and macrophages were significantly higher in allicin-treated mice. Allicin also promoted the maturation of CD11c+ DCs, while it did not cause major changes in IL-4 and the level of anti-inflammatory cytokine IL-10 (54-56).

Fenugreek is a common household item in special food preparation of Indians. Alkaloids and flavonoids derived from Fenugreek have been shown to inhibit the hemozoin formation and possess anti-plasmodial activity against chloroquine sensitive and resistant $P$. falciparum. It was found that fenugreek extract in a dose of 50,100 , or $250 \mathrm{mg} / \mathrm{kg}$ showed immunomodulatory property through various mechanisms including weight of thymus, delayed type of hypersensitivity response, humoral immunity and phagocytosis $(57,58,65,66)$. Peanuts, grapes, grape juice, and berries are common food consumed all over the world. Resveratrol, derived from the same have been shown to significantly reduce the ability of infected RBCs to adhere to the body's cells lining small blood vessels. Such phenomenon is predicted to greatly lessen the probability of developing severe clinical manifestations of malaria, according to the study (59).

Frequent consumption or decoction of medicinal plants by the people in malaria endemic areas has been shown to help fight the infection. Evidence for this came from the longitudinal study undertaken by Foundation for Revitalization of Local Health Traditions (FRLHT) in endemic regions of Odisha, Andhra Pradesh, and Chhattisgarh of India. It showed that traditional plant decoction taken by people (tribal and non-tribal) reduced the incidence of malaria by more than threefold (in communication, 67-69). Based on the actions of said compounds present in diet and/or in decoction, it is possible that parasite development is largely interrupted at the blood stage; in other words the Plasmodia infection among endemic populations, as in case of India, would preferentially be restricted to the liver stage helping provoke immune response against the LSAs. Therefore, we hypothesize that natural diet of people of different subcontinent could attenuate Plasmodia at different stages of infection and thus help provoke the immune responses against malaria liver-stage infection enhancing protection (Figure 3). Recent findings from the studies of vaccination of host using infectious sporozoite under the cover of chloroquine support the hypothesis.

\section{LESSONS FROM CHEMOPROPHYLAXIS STUDY WITH CHLOROQUINE AND DETERMINING FACTORS FOR PROTECTIVE IMMUNITY}

In endemic areas, people are repeatedly exposed to malaria parasite and control the infection with immune responses directed against the blood stage, as supported by majority of the investigations (2), or with the help of anti-malarial drugs. It is possible that interruption of parasite development at different stages, either in liver or in blood, by natural means or drug usage favors generation of liver-stage specific immune responses (Figure 4) (70). This possibility is revealed by the CPS immunization studies in mice and humans. In CPS immunization, three doses of parasite under chloroquine cover induce sterile protection that correlates with $\mathrm{CD}^{+} \mathrm{T}$ cell responses directed against the pre-erythrocytic stage of parasite $(7,8)$. In these studies, the immunized volunteers have been shown to be protected for up to 2 years. Similarly, it is

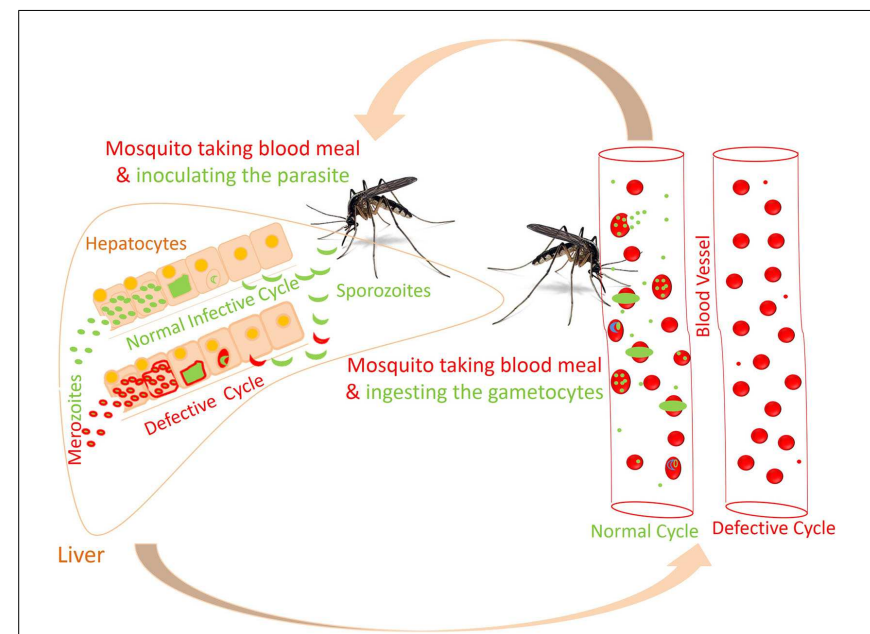

FIGURE 3 | Proposed altered life cycle of Plasmodium following consumption of diet containing anti-malarial compounds. Action of various compounds derived from diet is depicted in the figure. Green colored parasite represents normal life cycle while that of red colored parasite represents defective life cycle because of action of compounds present in diet. Possibilities: SPZ not able to infect the hepatocytes; parasite development is interrupted at initial or late stage in hepatocytes; or merozoites released might not able to infect the RBCs. Certain compounds in diet might attenuate the parasite following infection in RBCs.

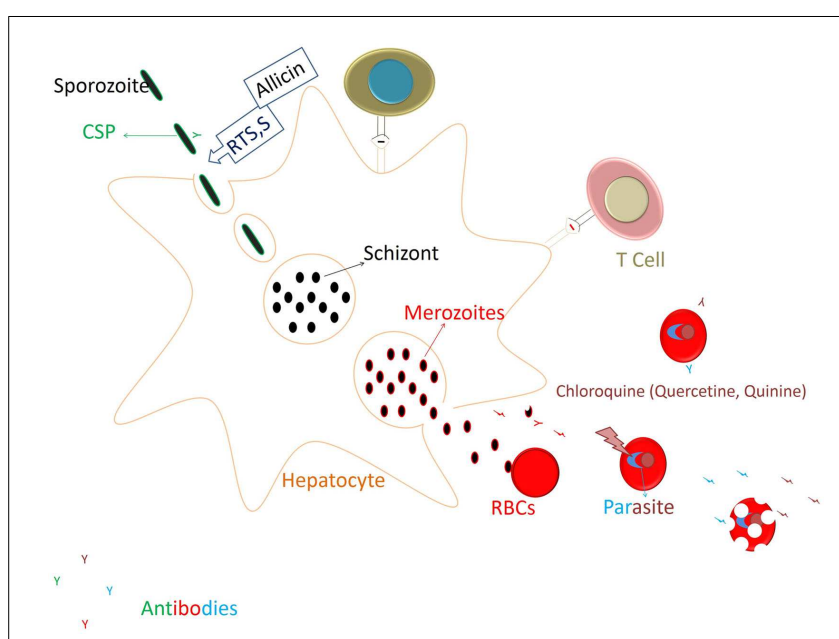

FIGURE 4 | Restricting the parasite development to Liver stage and generation of immune responses. RTS, S vaccines targeting the circumsporozoite protein (CSP) of the parasite generates mainly antibody responses against the CSP that acts on the sporozoite to prevent its invasion into hepatocytes. Allicin from the garlic cloves also would act in similar manner (prevention of hepatocyte invasion by spz) by eliminating CSP processing. After invading the hepatocyte sporozoite will undergo further development, and merozoites released infect the RBCs and start degrading $\mathrm{Hb}$. Heme released is polymerized to curtail its toxicity on the parasite. Chloroquine at this stage blocks the heme polymerization and kills the parasite. Thus, chloroquine (or compounds from food having similar action) would restrict the parasite development. Parasitic antigens released from the infected RBCs might generate the humoral and cellular responses to the blood stage parasite and also against the cross stage antigens from liver stage parasite (69). 
possible that compounds from dietary plants, as described above and medicinal decoction (during the diseased condition), would have similar actions like to Chloroquine. In fact, the effective antimalarial drugs we use today are derived from the plants. In malaria endemic areas, though maternal antibodies help fight the infection during their early life; children are highly prone to infection, which might be due to their developing immune system. Their susceptibility to malaria infection increases further probably for the fact that consumption of herbs and spices as part of food is quite low or rare in children, which increases as they grow. Hence, with the advancement of age, repeated exposure to the parasite, and frequent consumption of the herbs and spices might help to develop the protective immunity against the malaria, which is further supported by the observation that after several years of exposure to parasite children do develop immunity to the severe life threatening malaria (2).

Although blood stage specific immune responses seem to be dominating protection, the presence of liver-stage specific immune responses should not be underestimated. Possible reasons for not having noticeable liver-stage immunity among endemic population could be the low antigen availability and the tolerogenic environment in liver that keeps the inflammation under control. Hence in case of malaria, the parasite load and its frequency of exposure are the key factors to develop protective immunity against liver-stage infection. In natural exposure, the parasite load appears to be lower in endemic population compared to the immunization regimen in experimental studies. However, there is possibility of induction and building up of liver-stage specific immune responses in endemic populations over the years of exposures contributing to the protection (Figure 5). Many pre-clinical vaccine studies including ours support the above notion (71-73). In CPS immunization studies, it has been seen that three doses of parasite (sporozoite) immunization under the cover of chloroquine through i.v. route within short time period induce the sterile protection (26). While two doses of 20,000 sporozoite (spz) immunization protect $40 \%$ of mice, three doses of the same protect $100 \%$ of mice following infectious sporozoite challenge. Similar results were also found in our experiments using attenuated parasite $(\gamma$ $\mathrm{spz}$ ) immunization strategy (manuscript in preparation, 71). The higher level of protection correlates with the presence of higher number of multifunctional $\mathrm{CD} 8^{+} \mathrm{T}$ cells suggesting that multiple exposure to parasite antigens is required to achieve the protecting numbers of multifunctional $\mathrm{CD}^{+} \mathrm{T}$ cells (74). It is also possible that $\mathrm{CD}^{+} \mathrm{T}$ cell repertoire would be broadened for the subdominant antigens (antigens from various stages of development in liver) with repeated Ag exposure and ensue the protection against liver-stage malaria. Interestingly, it has been demonstrated that mice immunized with three doses of 10,000 spz under the cover of chloroquine were partially protected in contrast to mice that were given three doses of 20,000 spz (26). Further support came from the comparative studies in which the immunizations of attenuated parasites were done through intradermal (ID) vs. intravenous (IV) routes. ID route of immunization was thought to mimic the natural route of delivery of sporozoite through mosquito bite. It was

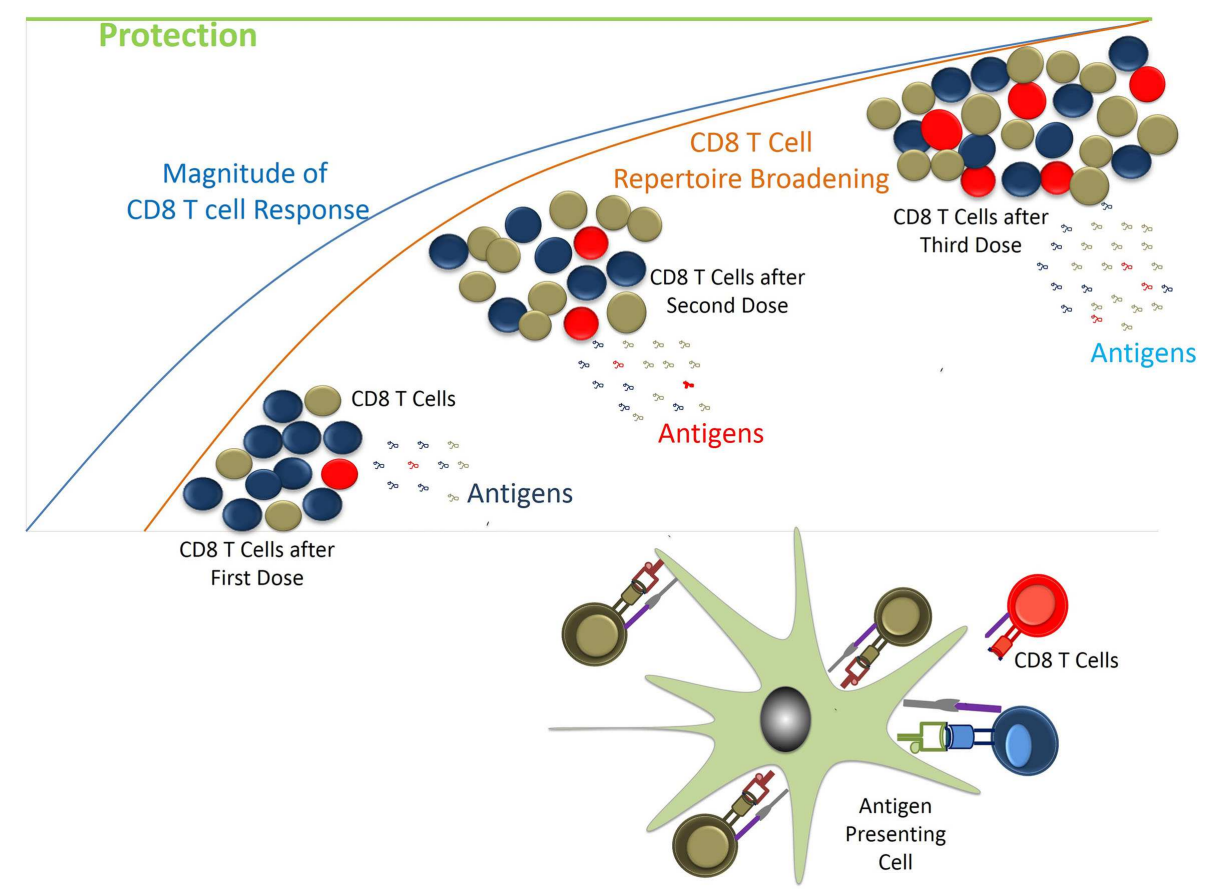

FIGURE 5 | Generation of CD8T cell response vs. protection. CD8T cells are generated following exposure to parasite antigens through natural infection. Depending on the availability and affinity of antigens CD8T cell clonotypes would have access to $\mathrm{MHC} / \mathrm{p}$ complexes. Initially $\mathrm{MHC} / \mathrm{p}$ in excess or with high affinity would preferentially induce the specific T cells.
During subsequent antigen exposures other antigens would come into picture while response to previously generated CD8T cells will be boosted. Gradually over time the desired repertoire of $\mathrm{T}$ cells with required frequencies would be generated helping protect the host from the incoming infection. 
found that immunization of mice through IV route was protective, while the same through ID route failed to protect the mice upon challenge (75). It has been demonstrated that parasite load in liver in case of ID immunization is very low compared to the IV (75) reflecting the low levels of the availability of antigens, which might be not sufficient to induce the desired magnitude of $\mathrm{CD}^{+} \mathrm{T}$ cells and to broaden the repertoire. To better understand the liver-stage specific immune responses, protected individuals in endemic areas should be included in large scale studies while CPS immunizations in humans could be taken as alternative positive control. Screening of protective antigens from those individuals will help the efforts of subunit vaccination.

\section{CONCLUSION}

Over a decade ago, the malaria genome was sequenced, which has revealed that the parasite contains over 5000 genes. Researchers around the globe are actively engaged in identifying and characterizing the genes. We have not yet been very successful in making effective vaccines, which could generate the protective immune responses against various developmental stages of Plasmodia infection. It is well known that multiple immune mechanisms are required to prevent the infection, e.g., $\mathrm{CD} 8^{+} \mathrm{T}$ cells are critical for liver-stage infection as parasite remains inside the hepatocytes while humoral response is the key mechanism in blood stage infection where antibodies are required to prevent the free merozoites to infect the RBCs (27). In addition, to prevent the sporozoite from invading the hepatocytes, we require neutralizing antibodies. Hence, a vaccine should be made, which could generate a diverse immune response. RTS,S is the most successful subunit vaccine available that produces the neutralizing antibodies against the CSP, present on the surface of sporozoite. Currently, whole sporozoite vaccines (RAS or GAS) are also becoming popular as they confer the sterile protection at least in experimental models by activating $\mathrm{CD}^{+} \mathrm{T}$ cells. Here, RAS are mainly restricted to initial stage while GAS are designed to be restricted at early, mid, or late in liver-stage development. Interestingly, chemoprophylaxis studies with chloroquine have shown the activation of both $\mathrm{CD} 8^{+}$ $\mathrm{T}$ cells and antibody response in which parasite is prevented at early blood stage (26).

Although we have understood mechanistically immune responses generated in animals or in experimental trials in humans, we have very little idea about the antigenic targets against which immune responses seems to be protective. And this is particularly true for liver-stage infection. Because there is lack of understanding of induction of protective immune response among endemic population against liver-stage infection, it has been very difficult to identify the targets. Therefore, systemic efforts must be made to understand liver-stage specific protective immune responses, particularly, in those populations living in malaria endemic area who are protected from the malaria by getting repeated exposure to the parasite. A recombinant protein of liver-stage parasite in adjuvant formulation will be an ideal formulation for mass scale immunization. A pre-erythrocytic stage vaccine should induce strong cellular immune response as well as develop long lasting immunological memory. New insight into parasite biology, stage specific expression profile, and characterization of carefully selected new antigens would provide new targets for interventions. Research institutes with focused $\mathrm{R} \& \mathrm{D}$ and skilled manpower must take the lead in the efforts to make vaccine against malaria by targeting antigens from multiple stages of Plasmodia infection.

\section{ACKNOWLEDGMENTS}

Thanks to Dr. Satyajit Rath, NII and Dr. K. V. S. Rao, ICGEB, New Delhi, India for critically reading the manuscript. We acknowledge DBT and DST (Govt. of India), GSBTM and GUJCOST (Govt. of Gujarat), NERF (Nirma Education and Research Foundation), and NII for supporting fellowships and research.

\section{REFERENCES}

1. World Health Organization. World Malaria Report 2008, 2009, 2010, 2011, 2012 and 2013. Available from: http://www.who.int/malaria/publications/en/

2. Doolan DL, Dobano C, Baird JK. Acquired immunity to malaria. Clin Microbiol Rev (2009) 22(1):13-36. doi:10.1128/CMR.00025-08

3. Marsh K, Kinyanjui S. Immune effector mechanisms in malaria. Parasite Immunol (2006) 28(1-2):51-60. doi:10.1111/j.1365-3024.2006.00808.x

4. Baird JK. Host age as a determinant of naturally acquired immunity to Plasmodium falciparum. Parasitol Today (1995) 11(3):105-11. doi:10.1016/01694758(95)80167-7

5. Butler NS, Vaughan AM, Harty JT, Kappe SH. Whole parasite vaccination approaches for prevention of malaria infection. Trends Immunol (2012) 33(5):247-54. doi:10.1016/j.it.2012.02.001

6. Seder RA, Chang LJ, Enama ME, Zephir KL, Sarwar UN, Gordon IJ, et al. Protection against malaria by intravenous immunization with a nonreplicating sporozoite vaccine. Science (2013) 341(6152):1359-65. doi:10.1126/science.1241800

7. Nganou-Makamdop K, van Gemert GJ, Arens T, Hermsen CC, Sauerwein RW. Long term protection after immunization with $P$. berghei sporozoites correlates with sustained IFNgamma responses of hepatic CD8+ memory T cells. PLoS One (2012) 7(5):e36508. doi:10.1371/journal.pone.0036508

8. Roestenberg M, McCall M, Hopman J, Wiersma J, Luty AJ, van Gemert GJ, et al. Protection against a malaria challenge by sporozoite inoculation. $N$ Engl J Med (2009) 361(5):468-77. doi:10.1056/NEJMoa0805832

9. Gordon DM, McGovern TW, Krzych U, Cohen JC, Schneider I, LaChance R, et al. Safety, immunogenicity, and efficacy of a recombinantly produced Plasmodium falciparum circum sporozoite protein-hepatitis B surface antigen subunit vaccine. J Infect Dis (1995) 171(6):1576-85. doi:10.1093/infdis/171.6.1576

10. Stoute JA, Slaoui M, Heppner DG, Momin P, Kester KE, Desmons P, et al. A preliminary evaluation of a recombinant circumsporozoite protein vaccine against Plasmodium falciparum malaria. RTS,S malaria vaccine evaluation group. NEngl J Med (1997) 336(2):86-91. doi:10.1056/NEJM199701093360202

11. Kester KE, McKinney DA, Tornieporth N, Ockenhouse CF, Heppner DG, Hall T, et al. Efficacy of recombinant circumsporozoite protein vaccine regimens against experimental Plasmodium falciparum malaria. J Infect Dis (2001) 183(4):640-7. doi:10.1086/318534

12. Kester KE, McKinney DA, Tornieporth N, Ockenhouse CF, Heppner DG Jr, Hall $\mathrm{T}$, et al. A phase I/IIa safety, immunogenicity, and efficacy bridging randomized study of a two-dose regimen of liquid and lyophilized formulations of the candidate malaria vaccine RTS,S/AS02A in malaria-naive adults. Vaccine (2007) 25(29):5359-66. doi:10.1016/j.vaccine.2007.05.005

13. Schofield L, Hewitt MC, Evans K, Siomos MA, Seeberger PH. Synthetic GPI as a candidate anti-toxic vaccine in a model of malaria. Nature (2002) 418(6899):785-9. doi:10.1038/nature00937

14. Sagara I, Dicko A, Ellis RD, Fay MP, Diawara SI, Assadou MH, et al. A randomized controlled phase 2 trial of the blood stage AMA1-C1/Alhydrogel malaria vaccine in children in Mali. Vaccine (2009) 27(23):3090-8. doi:10.1016/j.vaccine.2009. 03.014

15. Naik RS, Krishnegowda G, Ockenhouse CF, Gowda DC. Naturally elicited antibodies to glycosylphosphatidylinositols (GPIs) of Plasmodium falciparum require intact GPI structures for binding and are directed primarily against the conserved glycan moiety. Infect Immun (2006) 74(2):1412-5. doi:10.1128/IAI. 74.2.1412-1415.2006

16. Bull PC, Lowe BS, Kortok M, Molyneux CS, Newbold CI, Marsh K. Parasite antigens on the infected red cell surface are targets for naturally acquired immunity to malaria. Nat Med (1998) 4(3):358-60. doi:10.1038/nm0398-358 
17. Crompton PD, Pierce SK, Miller LH. Advances and challenges in malaria vaccine development. J Clin Invest (2010) 120(12):4168-78. doi:10.1172/ JCI44423

18. Ogutu BR, Apollo OJ, McKinney D, Okoth W, Siangla J, Dubovsky F, et al. Blood stage malaria vaccine eliciting high antigen-specific antibody concentrations confers no protection to young children in Western Kenya. PLoS One (2009) 4(3):e4708. doi:10.1371/journal.pone.0004708

19. Weedall GD, Conway DJ. Detecting signatures of balancing selection to identify targets of anti-parasite immunity. Trends Parasitol (2010) 26(7):363-9. doi:10.1016/j.pt.2010.04.002

20. Wang R, Smith JD, Kappe SH. Advances and challenges in malaria vaccine development. Expert Rev Mol Med (2009) 11:e39. doi:10.1017/S1462399409001318

21. van Schaijk BC, Janse CJ, van Gemert GJ, van Dijk MR, Gego A, Franetich JF, et al. Gene disruption of Plasmodium falciparum 552 results in attenuation of malaria liver stage development in cultured primary human hepatocytes. PLoS One (2008) 3(10):e3549. doi:10.1371/journal.pone.0003549

22. van Dijk MR, Douradinha B, Franke-Fayard B, Heussler V, van Dooren MW, van Schaijk B, et al. Genetically attenuated, P36p-deficient malarial sporozoites induce protective immunity and apoptosis of infected liver cells. Proc Natl Acad Sci U S A (2005) 102(34):12194-9. doi:10.1073/pnas.0500925102

23. Dieye A, Rogier C, Trape J-E, Sarthou J-L, Druilhe R. HLA class I-associated resistance to severe malaria: a parasitological re-assessment. Parasitol Today (1997) 13(2):48-9. doi:10.1016/S0169-4758(96)20062-6

24. Sagara I, Sangaré D, Dolo G, Guindo A, Sissoko M, Sogoba M, et al. A high malaria reinfection rate in children and young adults living under a low entomological inoculation rate in a peri-urban area of Bamako, Mali. Am J Trop Med Hyg (2002) 66(3):310-3.

25. Owusu-Agyei S, Koram KA, Baird JK, Utz GC, Binka FN, Nkrumah FK, et al. Incidence of symptomatic and asymptomatic Plasmodium falciparum infection following curative therapy in adult residents of Northern Ghana. Am J Trop Med Hyg (2001) 65(3):197-203.

26. Brando C, Richardson JH, Murphy J, Ockenhouse CF, Kamau E. Phenotypic characterization of Plasmodium berghei responsive CD8+ T cells after immunization with live sporozoites under chloroquine cover. Malar J (2014) 13:92. doi:10.1186/1475-2875-13-92

27. Langhorne J, Ndungu FM, Sponaas AM, Marsh K. Immunity to malaria: more questions than answers. Nat Immunol (2008) 9(7):725-32. doi:10.1038/ni.f.205

28. Connelly M, King CL, Bucci K, Walters S, Genton B, Alpers MP, et al. T-cell immunity to peptide epitopes of liver-stage antigen 1 in an area of Papua New Guinea in which malaria is holoendemic. Infect Immun (1997) 65(12): 5082-7.

29. Aidoo M, Lalvani A, Gilbert SC, Hu JT, Daubersies P, Hurt N, et al. Cytotoxic T-lymphocyte epitopes for HLA-B53 and other HLA types in the malaria vaccine candidate liver-stage antigen 3. Infect Immun (2000) 68(1):227-32. doi:10.1128/IAI.68.1.227-232.2000

30. National Vector Borne Disease Control Programme, Govt. of India. Malaria Situation in India. Available from: http://nvbdcp.gov.in/malaria-new.html; http: //nvbdcp.gov.in/Doc/mal_situation_Dec2014.pdf

31. Helgi Library Available from: http://www.helgilibrary.com/indicators/index/ spice-consumption-per-capita

32. Uma Pradeep K, Geervani P, Eggum BO. Common Indian spices: nutrient composition, consumption and contribution to dietary value. Plant foods for human. Nutrition (1993) 44:137-48.

33. Anand P, Kunnumakkara AB, Newman RA, Aggarwal BB. Bioavailability of curcumin: problems and promises. Mol Pharm (2007) 4(6):807-18. doi:10.1021/ mp700113r

34. Ferrucci LM, Daniel CR, Kapur K, Chadha P, Shetty H, Graubard BI, et al. Measurement of spices and seasonings in India: Opportunities for cancer epidemiology and prevention. Asian Pac J Cancer Prev (2010) 11(6):1621-9.

35. Manu S, Deshmukh R, Prasad KMN, Trivedi V. Screening and characterization of antimalarial heme polymerase inhibitors from garlic cloves. Eur J Med Plants (2013) 3:474-84. doi:10.9734/EJMP/2013/4644

36. Trotta RF, Brown ML, Terrell JC, Geyer JA. Defective DNA repair as a potential mechanism for the rapid development of drug resistance in Plasmodium falciparum. Biochemistry (2004) 43(17):4885-91. doi:10.1021/bi0499258

37. Egan TJ, Ncokazi KK. Quinolineantimalarials decrease the rate of beta-hematin formation. J Inorg Biochem (2005) 99(7):1532-9. doi:10.1016/j.jinorgbio.2005. 04.013
38. Soh PN, Witkowski B, Olagnier D, Nicolau ML, Garcia-Alvarez MC, Berry A, et al. In vitro and in vivo properties of ellagic acid in malaria treatment. Antimicrob Agents Chemother (2009) 53(3):1100-6. doi:10.1128/AAC.01175-08

39. Sturm N, Hu Y, Zimmermann H, Fritz-Wolf K, Wittlin S, Rahlfs S, et al. Compounds structurally related to ellagic acid show improved antiplasmodial activity. Antimicrob Agents Chemother (2009) 53(2):622-30. doi:10.1128/AAC. 00544-08

40. Bagalkotkar G, Sagineedu SR, Saad MS, Stanslas J. Phytochemicals from Phyllanthus niruri linn. and their pharmacological properties: a review. J Pharm Pharmacol (2006) 58(12):1559-70. doi:10.1211/jpp.58.12.0001

41. Vos AP, M'Rabet L, Stahl B, Boehm G, Garssen J. Immune-modulatory effects and potential working mechanisms of orally applied nondigestible carbohydrates. Crit Rev Immunol (2007) 27(2):97-140. doi:10.1615/CritRevImmunol. v27.i2.10

42. Rodrigues T, Lopes F, Moreira R. Inhibitors of the mitochondrial electron transport chain and de novo pyrimidine biosynthesis as antimalarials: the present status. Curr Med Chem (2010) 17(10):929-56. doi:10.2174/092986710790820660

43. Nishi Gupta GV, Ankita W, Pranay W. Antimalarials from semisynthetic origin. Pharma Sci Mon (2013) 4(3):377-404.

44. Lal J. Turmeric, curcumin and our life: a review. Bull Environ Pharmacol Life Sci (2012) 1:11-7.

45. Tayyem RF, Heath DD, Al-Delaimy WK, Rock CL. Curcumin content of turmeric and curry powders. Nutr Cancer (2006) 55(2):126-31. doi:10.1207/ s15327914nc5502_2

46. Nandakumar DN, Nagaraj VA, Vathsala PG, Rangarajan P, Padmanaban G. Curcumin-artemisinin combination therapy for malaria. Antimicrob Agents Chemother (2006) 50(5):1859-60. doi:10.1128/AAC.50.5.1859-1860.2006

47. Cui L, Miao J, Cui L. Cytotoxic effect of curcumin on malaria parasite Plasmodium falciparum: inhibition of histone acetylation and generation of reactive oxygen species. Antimicrob Agents Chemother (2007) 51(2):488-94. doi:10.1128/AAC.01238-06

48. Mimche PN, Taramelli D, Vivas L. The plant-based immunomodulator curcumin as a potential candidate for the development of an adjunctive therapy for cerebral malaria. Malar J (2011) 10(Suppl 1):S10. doi:10.1186/1475-2875-10S1-S10

49. Chainani-Wu N. Safety and anti-inflammatory activity of curcumin: a component of turmeric (Curcuma longa). JAltern Complement Med (2003) 9(1):161-8. doi:10.1089/107555303321223035

50. Sharma RA, Euden SA, Platton SL, Cooke DN, Shafayat A, Hewitt HR, et al. Phase I clinical trial of oral curcumin: biomarkers of systemic activity and compliance. Clin Cancer Res (2004) 10:6847-54. doi:10.1158/1078-0432.CCR-04-0744

51. Pan MH, Huang TM, Lin JK. Biotransformation of curcumin through reduction and glucuronidation in mice. Drug Metab Dispos (1998) 27(1):486-94.

52. Block W. Cinnamon Reduces Hemoglobin A1c and Blood Glucose. (2012). Available from: http://www.life-enhancement.com/magazine/article/ 2770-cinnamon-reduces-hemoglobin-alc-and-blood-glucose

53. Sharma P. Cinnamic acid derivatives: a new chapter of various pharmacological activities. J Chem Pharm Res (2011) 3(2):403-23.

54. Coppi A, Cabinian M, Mirelman D, Sinnis P. Antimalarial activity of allicin, a biologically active compound from garlic cloves. Antimicrob Agents Chemother (2006) 50(5):1731-7. doi:10.1128/AAC.50.5.1731-1737.2006

55. Feng Y, Zhu X, Wang Q, Jiang Y, Shang H, Cui L, et al. Allicin enhances host proinflammatory immune responses and protects against acute murine malaria infection. Malar J (2012) 11:268. doi:10.1186/1475-2875-11-268

56. Ankri S, Mirelman D. Antimicrobial properties of allicin from garlic. Microbes Infect (1999) 1(2):125-9. doi:10.1016/S1286-4579(99)80003-3

57. Saxena SN, Karwa S, Saxena R, Sharma T, Sharma YK, Kakani RK, et al. Analysis of antioxidant activity, phenolic and flavanoids content of fenugreek (Trigonellafoenum-graecum L.) seed extracts. Int J Seed Spices (2011) 1(1):38-43.

58. Palaniswamy M, Pradeep BV, Sathya R, Angayarkanni J. In vitro anti-plasmodial activity of Trigonellafoenum-graecum L. Evid Based Complement Alternat Med (2010) 7(4):441-5. doi:10.1093/ecam/nen030

59. Lesh M. Substance Found in Red Wine May Help Treat Malaria. American Society of Tropical Medicine and Hygiene (2010). Available from: https:// www.astmh.org/AM/Template.cfm?Section=Press_Releases\&Template=/CM/ ContentDisplay.cfm\&ContentID $=2868$

60. Ginger. Herbal Encyclopedia. Available from: www.cloverleaffarmherbs.com/ ginger/\#sthash.UnYnjcjy.dpbs 
61. Walling E. Learn About the Many Benefits of Lauric Acid in Coconut Oil. Natural News (2009). Available from: http://www.naturalnews.com/026819_lauric_ acid_coconut_oil_infections.html

62. Carballeira NM. New advances in fatty acids as antimalarial, anti-mycobacterial and antifungal agents. Prog Lipid Res (2008) 47(1):50-61. doi:10.1016/j.plipres. 2007.10.002

63. Soh PN, Witkowski B, Gales A, Huyghe E, Berry A, Pipy B, et al. Implication of glutathione in the in vitro antiplasmodial mechanism of action of ellagic acid. PLoS One (2012) 7(9):e45906. doi:10.1371/journal.pone.0045906

64. Hata K, Ogawa K, Tsukada I, Nakamoto K, Sagane K, Tanaka K, et al., Inventors; EISAI CO., Ltd., assignee. Methods of Screening for Compounds that Inhibit the Biosynthesis of gpi in Malaria Parasites. United States patent US WO2004048567 (2004).

65. Meghwal M, Goswami TKA. Review on the functional properties, nutritional content, medicinal utilization and potential application of fenugreek. J Food Process Technol (2012) 3:181. doi:10.4172/2157-7110.1000181

66. Kaur J, Singh H, Khan MU. Multifarious therapeutic potential of fenugreek: a comprehensive review. Int J Res Pharm Biomed Sci (2011) 2(3): 863-71.

67. Foundation for Revitalization of Local Health Traditions (FRLHT) Annual Report, 2007. Available from: http://www.researchgate.net/profile/Prakash_ BN2/publication/233780529_Traditional_Herbal_Medicine_for_Malaria_ Prevention/links/0fcfd50b6eb46189d9000000.pdf

68. Nagendrappa PB, Naik MP, Payyappallimana U. Ethnobotanical survey of malaria prophylactic remedies in Odisha, India. J Ethnopharmacol (2013) 146:768-72. doi:10.1016/j.jep.2013.02.003

69. Nagendrappa PB, Naik MP, Toppo J, Haridasan K, Venkatasubramanian P. Traditional phytotherapy for prevention of malaria in Jashpur District, Chhattisgarh. Int J Indigenous Med Plants (2013) 46(3):1294-300.

70. Belnoue E, Voza T, Costa FT, Gruner AC, Mauduit M, Rosa DS, et al. Vaccination with live Plasmodium yoelii blood stage parasites under chloroquine cover induces cross-stage immunity against malaria liver stage. J Immunol (2008) 181(12):8552-8. doi:10.4049/jimmunol.181.12.8552

71. Zarling S, Berenzon D, Dalai S, Liepinsh D, Steers N, Krzych U. The survival of memory CD8 $\mathrm{T}$ cells that is mediated by IL- 15 correlates with sustained protection against malaria. J Immunol (2013) 190(10):5128-41. doi:10.4049/ jimmunol.1203396

72. Schmidt NW, Butler NS, Harty JT. CD8 T cell immunity to Plasmodium permits generation of protective antibodies after repeated sporozoite challenge. Vaccine (2009) 27(44):6103-6. doi:10.1016/j.vaccine.2009.08.025

73. Hafalla JC, Sano G, Carvalho LH, Morrot A, Zavala F. Short-term antigen presentation and single clonal burst limit the magnitude of the CD8 $(+) \mathrm{T}$ cell responses to malaria liver stages. Proc Natl Acad Sci U S A (2002) 99(18):11819-24. doi:10.1073/pnas.182189999

74. Schmidt NW, Podyminogin RL, Butler NS, Badovinac VP, Tucker BJ, Bahjat KS, et al. Memory CD8 T cell responses exceeding a large but definable threshold provide long-term immunity to malaria. Proc Natl Acad Sci U S A (2008) 105(37):14017-22. doi:10.1073/pnas.0805452105

75. Nganou-Makamdop K, Ploemen I, Behet M, Van Gemert GJ, Hermsen C, Roestenberg M, et al. Reduced Plasmodium berghei sporozoite liver load associates with low protective efficacy after intradermal immunization. Parasite Immunol (2012) 34(12):562-9. doi:10.1111/pim.12000.x

Conflict of Interest Statement: The authors declare that the research was conducted in the absence of any commercial or financial relationships that could be construed as a potential conflict of interest.

Received: 11 December 2014; accepted: 06 March 2015; published online: 20 March 2015 .

Citation: Dalai SK, Yadav N, Patidar M, Patel H and Singh AP (2015) Liver-stage specific response among endemic populations: diet and immunity. Front. Immunol. 6:125. doi: 10.3389/fimmu.2015.00125

This article was submitted to Microbial Immunology, a section of the journal Frontiers in Immunology.

Copyright (c) 2015 Dalai, Yadav, Patidar, Patel and Singh. This is an open-access article distributed under the terms of the Creative Commons Attribution License (CC BY). The use, distribution or reproduction in other forums is permitted, provided the original author(s) or licensor are credited and that the original publication in this journal is cited, in accordance with accepted academic practice. No use, distribution or reproduction is permitted which does not comply with these terms. 